behaviour of metals on the surfaces of cupels when undergoing cupellation in the process by which gold bullion is assayed. When the surface tension of the metal is lowered by the presence of tellurium, I have shown that the 'cupellation losses', normally allowed for by suitable 'checks', may, in extreme cases, be such that complete absorption of the metal by the cupel may occur ${ }^{3}$.

7 De Vere Gardens,

S. W. SMrrth

London, W.8.

June 2.

1 J. Inst. Metals, 12, Noo. 2, 168 (1914).

$2 J$. Inst. Metals, 12, No. 2, 205 (1914).

Trans. Inst. Min. and Metal., 463 (1908).

\section{Discontinuities in Supercooled Ionic Melts}

DURING the course of a systematic investigation on the electrochemistry of boron trifluoride co-ordination compounds ${ }^{1}$, discontinuities were observed in the temperature variation of viscosity on passing from the normal liquid to the supercooled state. In both tem. perature regions the viscosity could be expressed by an exponential relation of the form $\eta=\eta_{0} \exp (B / R T)$, but the activation energy $B$ was approximately 10 per cent greater for the supercooled state. The ternperature coefficient of the specific volume $(v)$ shows no such discontinuity at the melting point, and this fact may be used for emphasizing the discontinuous behaviour of the viscosity by the application of Batchinski's equation ${ }^{2} \eta=C /(v-b)$, where $C$ and $B$ are constants. For example, if the fluidity $\varphi=1 / \eta$ is plotted as a function of specific volume for acetoxytrifluoroboric acid, $\mathrm{H}\left[\mathrm{CH}_{3} . \mathrm{CO} . \mathrm{OBF}_{3}\right]$, there is a well-defined discontinuity at a point corresponding to the melting point, $37 \cdot 5^{\circ} \mathrm{C}$. The change in slope is 34 per cent, compared with an increase of 10 per cent for the activation energy $B$ for this compound.

As boron trifluoride complexes are systems for which the activation energies of ionic migration are very similar to those of viscous flow ${ }^{3,4}$, it is likely that

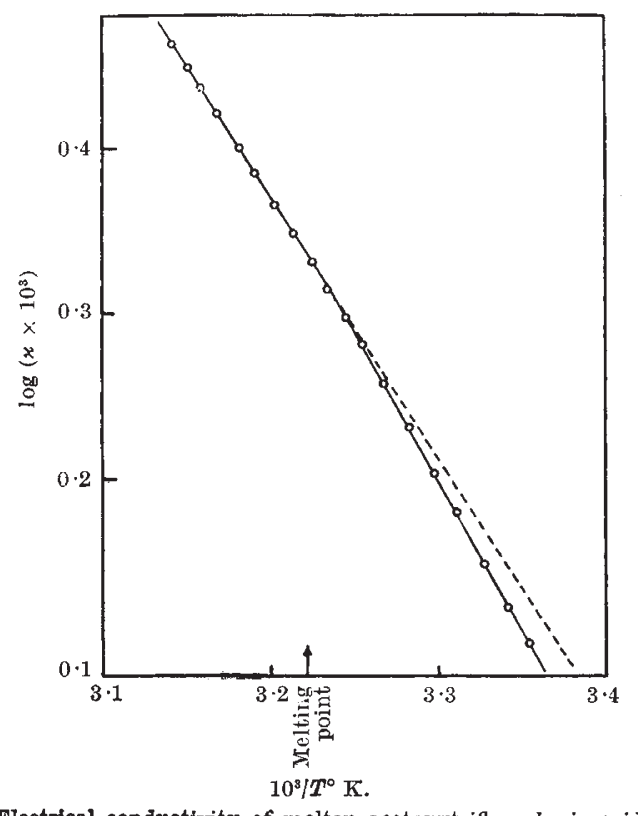

Electrical conductivity of molten acetoxytrifluoroboric acid similar configurational changes occur in the two processes and that ionic mobility at various tem. peratures will be proportional to the viscosity. It might therefore be expected that the specific con. ductivity of such liquids would show a corresponding effect at the melting point. This is, in fact, the case, as may be seen from the accompanying graph, in which $\log x$ is plotted against $1 / T$ for molten acetoxytrifluoroboric acid. The increase in slope at the melting point is 13 per cent. A graph of specific conductivity as a function of specific volume shows the same phenomenon.

The ionic compounds formed by boron trifluoride with methyl, ethyl, $n$-propyl and $n$-butyl acetates behave in a precisely analogous fashion to the addition compound with acetic acid considered above. The effect, however, is not confined to ionic melts, as Dodd and Hu Pak Mis have shown that plots of $\log \eta$ against $1 / T^{\prime}$ for phenyl ether and $m$-chloronitrobenzene are discontinuous at the melting point. It is consequently of interest to determine whether or not these effects are general in supercooled melts. The data on such systems are rather scattered, but a recalculation of available information shows that the same trend is implicit in the figures of Walden, Ulich and Birr ${ }^{6}$ for the viscosity and conductivity of certain molten picrates.

A fuller discussion will be published elsewhere.

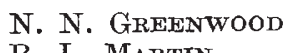

R. L. Martin

University Chemical Laboratory,

$$
\text { Cambridge. }
$$
April 6.

${ }^{1}$ Greenwood, N. N., and Martin, R. I., J. Chem. Soc. (in the press).

${ }^{a}$ Batchinski, A. J., Z. phys. Chem., 84, 643 (1913).

${ }^{3}$ Greenwood, N. N., Martin, R. L., and Emeléus, H. J., J. Chem. Soc., $3030(1950)$

${ }^{4}$ Greenwood, N. N., and Martin, R. L., J. Chem. Soc. (in the press),

${ }_{5}^{5}$ Dodd, C., and Hu Pak Mi, Proc. Phys. Soc., B, 65, 454 (1949).

${ }^{*}$ Walden, P., Ulich, H., and Birr, E. J., Z. phys. Chem., 131, 1 and 21 (1927).

\section{Dimensions of the Nitrite Ion}

As part of a programme of $\mathrm{X}$-ray investigations of $\mathrm{N}-\mathrm{O}$ bond-lengths and angles, and in particular for comparison of the bond-lengths in the positive (nitronium) ${ }^{1}$ and negative (nitrite) $\mathrm{NO}_{2}$ ions, the structure of sodium nitrite ${ }^{2}$ has been redetermined.

Three-dimensional and differential Fourier syntheses (corrected for termination of series errors) give the following dimensions for the nitrite ion :

$$
\begin{array}{lll}
\text { Bond-length } & \mathrm{N}-\mathrm{O} & 1 \cdot 13(9) \\
\text { Angle } & \mathrm{O}-\mathrm{N}-\mathrm{O} & 132^{\circ} 48^{\prime}
\end{array}
$$

The root mean square error in the bond-length calculated by the method of Cruickshank ${ }^{3}$ is $\pm 0.01 \mathrm{~A}$., so that the value of $1 \cdot 14 \mathrm{~A}$. now found is not significantly different from the value of 1.15 A. for $\mathrm{O}-\mathrm{N}$ in the nitronium ion in nitrogen pentoxide ${ }^{4}$.

Full details of the determination will be published together with those for nitronium perchlorate, which is still under investigation.

\footnotetext{
Chemistry Department,

University of Leeds. July 25.

${ }^{1}$ Cox, E. G., Jeffrey, G. A., and Truter, M. R., Nature, 162, 259 (1948). ${ }^{2}$ Ziegler, G. E., Phys. Rev., 38, 1040 (1931).

${ }^{3}$ Cruickshank, D. W. J., Acta Cryst., 2, 65 (1949).

4 Grison, E., Eriks, K., and Vries, J. L., Acta Cryst., 3, 290 (1950).
} 